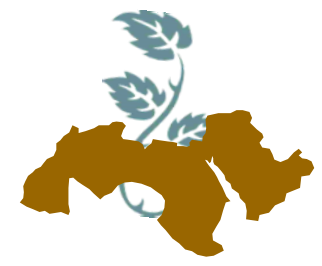

\title{
THE EFFECT OF HEAT STRESS ON PRODUCTIVE TRAITS FOR THREE EGYPTIAN BREEDS
}

\author{
Habiba. H. Rezk, H.E. Ayeoub, A. Galal and Lamiaa, M. Radwan \\ Poultry Production Dept., Fac. of Agric., Ain Shams Univ., Cairo, Egypt
}

Keywords: Heat stress, productive traits, Egyptian local breeds

\section{ABSTRACT}

The objective of the present study the effects of heat stress on the productive traits are Play an important role in the poultry industry. The experiment was carried out in the farm of the Faculty of Agriculture-Ain Shams University, reared 600 chick of three breeds (Sinai - Fayoumi - Dandrawi) were divided into equal two groups (the treatment was exposed to heat stress on different periods of 3 days - 8 weeks - 16 weeks on temperature of $40^{\circ} \mathrm{C}$ for 4 hours / 3 days. While, the control under environmental conditions. Then, take the body weight in $8,10,12,14,16$ weeks of ages, and body measurements (shank length, tibia length, body depth, keel length, comb and wattle) in three local breeds. The most important results obtained that It could be observed that the effect was high significantly $(p<0.0001)$ heavier in Fayoumi compared to Dandarawi and Sinai in weight body and The results in the body measurements of the parent stock showed The effect on the Fayoumi breed was higher followed by Dandarawi and Sinai, The effect of the rectal temperature and rate respiratory are significant on the breed and the treatment. Concluded that study the effect on productive traits for three local breeds.

\section{INTRODUCTION}

Heat stress is one of the most challenging environmental conditions affecting poultry production. Recent years have seen Global climate change, elevated temperatures and the increased occurrence of heat waves will cause stress in poultry resulting in reduced productivity and increase mortality rate (Turnpenny et al 2001). According to recent surveys, the heat stress is a major problem of poultry production due to of poultry does not contain sweat glands and containing layer fatty subcutaneous resulting difficulty in getting rid of high temperatures and as a result, lead to a huge loss of both laying and broiler stocks (Obike et al 2016). The heat stress reflected a negative balance between the net amount of energy flowing from the animal's body of its surrounding environment and the amount of heat energy produced by the animal. This imbalance may be caused by variations on a combination of environmental factors (sunlight, thermal irradiation, air temperature, humidity, and movement), and characteristics of the animal (species, metabolism rate, and thermoregulatory mechanisms). Environmental stressors, such as heat stress, are particularly detrimental to animal agriculture. The issue of environmental stress has quickly become a great point of interest in animal agriculture, particularly due to public awareness and concerns. The importance of animal responses to environmental challenges applies to all species. However, poultry seems to be particularly sensitive to temperature-associated environmental challenges, especially heat stress. It has been suggested that modern poultry genotypes produce more body temperature, due to their greater metabolic activity. Understanding and controlling environmental conditions is successful poultry production and welfare. The topic of heat stress in poultry production can be described as 'acute' or 'chronic'; acute heat stress refers to short and sudden periods of extremely high temperature, whereas chronic heat stress refers to extended periods of elevated temperature (Emery, 2004). It has been shown that heat stress has detrimental effects on the performance of 4-8 wk old broiler birds reared in the open-sided poultry houses; principally through reducing feed intake, growth rate, negatively affect feed efficiency and carcass quality as well as health (Carmen et al 1991; Yahav \& Hurwitz, 1996 and Younis et al 2003). Moreover, chronic 
heat stress increases the time to reach market weight and increase mortality rate (Howlider \& Rose, 1989 and Ozbey \& Ozceilik, 2004). Poultry production of hot climates is increasing in response to multiple factors. As climate changes, the weather affecting the major centers of chicken production is expected to become warmer (Meehl and Tebaldi, 2004). Breeding of birds that are genetically more resistant to heat stress will lessen these effects(Renaudeau et al 2012). The objective of the present study effect heat stress on productive traits for local breeds.

\section{MATERIALS AND METHODS}

\section{Experimental design}

The experiment was designed reared 600 chick of three strains (Sinai - Fayoumi - Dandrawi) were divided into equal two groups the first group called to treatment group, the treatment group was exposed to heat stress on different periods of 3 days - 8 weeks - 16 weeks on temperature of 400 c for 4 hours / 3 days. While, the second groups control group was reared ideal environmental conditions.

\section{Heat tolerance test}

Heat tolerance test included (respiratory rate, rectal temperature) were measured at 3 days, 8 and 16 weeks of age. The respiratory rate was measured by counting the panting breaths of the birds for $1 \mathrm{~min}$. While, the rectal temperature was obtained by introducing a digital thermometer into the cloaca of each bird until the reading stabilized

\section{Productive traits}

\section{Body weight}

Individual body weight (in gram) was recorded for each sex separately within each breed at $8,10,12,14$ and 16 weeks of age.

\section{Body measurement}

Body measurements included (shank length, tibia length, keel length, body depth and length both comb and wattle) were measured for each sex separately within each breed at 8,12 and16 weeks of age by a digital caliber and measured comb and wattle length by using Ruler.

\section{Statistical analysis}

Data were subjected to three -way analysis of variance between breed, treatment and age factors. Their interaction using the General Linear Models (GLM) procedure of SAS User's Guide, Ver.8.2, 2001. Duncan's multiple range tests were used to test differences among means according to Duncun (1955) separate means when separation was relevant.

The three-way analysis of variance model interaction:

$Y_{i j k}=\mu+T_{i}+B_{j}+A_{k}+(T B)_{i j}+(B A)_{j k}+(T A)_{i k}+(T B A)_{i j k}$ $+\mathrm{e}_{\mathrm{ijk}}$

$\mu=$ Ovellall mean, $B_{j}=$ Breed effect, $A_{k}=$ Age effect, $\mathrm{T}_{\mathrm{i}}=$ Treatment effect, $\mathrm{TBA}_{\mathrm{ijk}}=$ Interaction between Breed and Treatment and age , $e_{i j k}=$ Experimental error.

\section{RESULTS AND DISCUSSION}

\section{Productive traits}

\section{Body weight}

Figures $(1,2)$ show the heat tolerance measurement (Rectal temperature and respiratory rate responses) for Sinai, Dandarawi and Fayoumi for parent stock. As shown Fig. (1) respiratory rate of Sinai, Dandarawi and Fayoumi under heat at different age for parent stock. The results showed that the male Fayoumi breed was high significant at different age compared to Sinai and Dandarwi ones. But, the female showed that Sinai breed was significant compared to Fayoumi and Dandarwi ones. As shown .fig (2) rectal temperature of Sinai, Dandarawi and Fayoumi for parent stock was not a significant effect of breeds and treatment. Arjona et al (1990) and Elbashir et al (2001) found no significant differences in the body temperature of acclimated and non-acclimated birds. Arad and Marder (1982) reported that acclimation to heat stress led to decrease rectal temperature and respiration rate. Blagojevic (2007) founded that exposure to low-temperature provokes physiological responses related to oxygen consumption and induces changes in energy production and subsequent reactive oxygen species (ROS) production. Walsh et al (1971) reported that heat stress led to increase rectal temperature and respiration rate. 


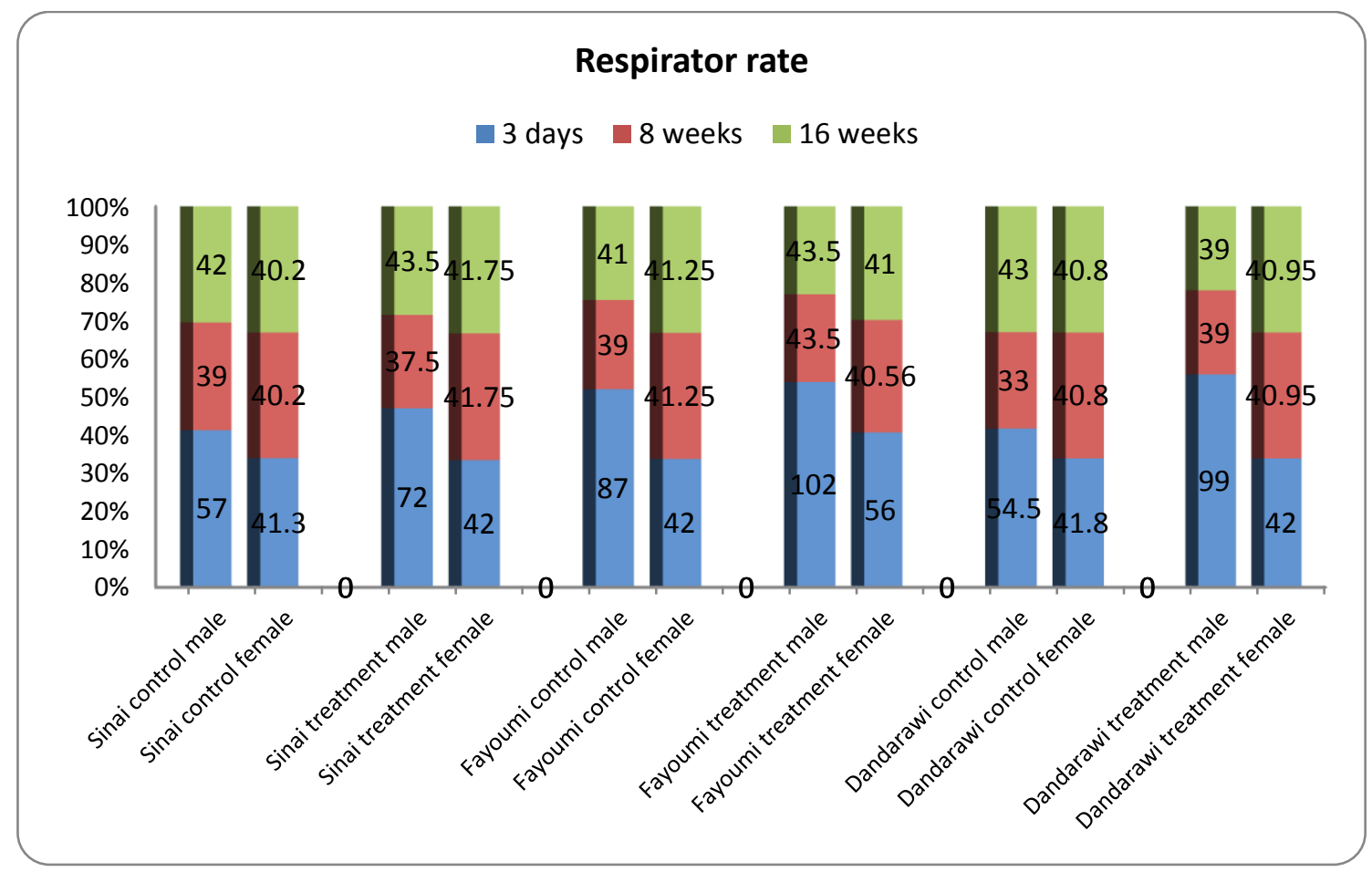

Fig. 1. Respiratory rate of Sinai, Dandarawi and Fayoumi under heat at different age for parent stock

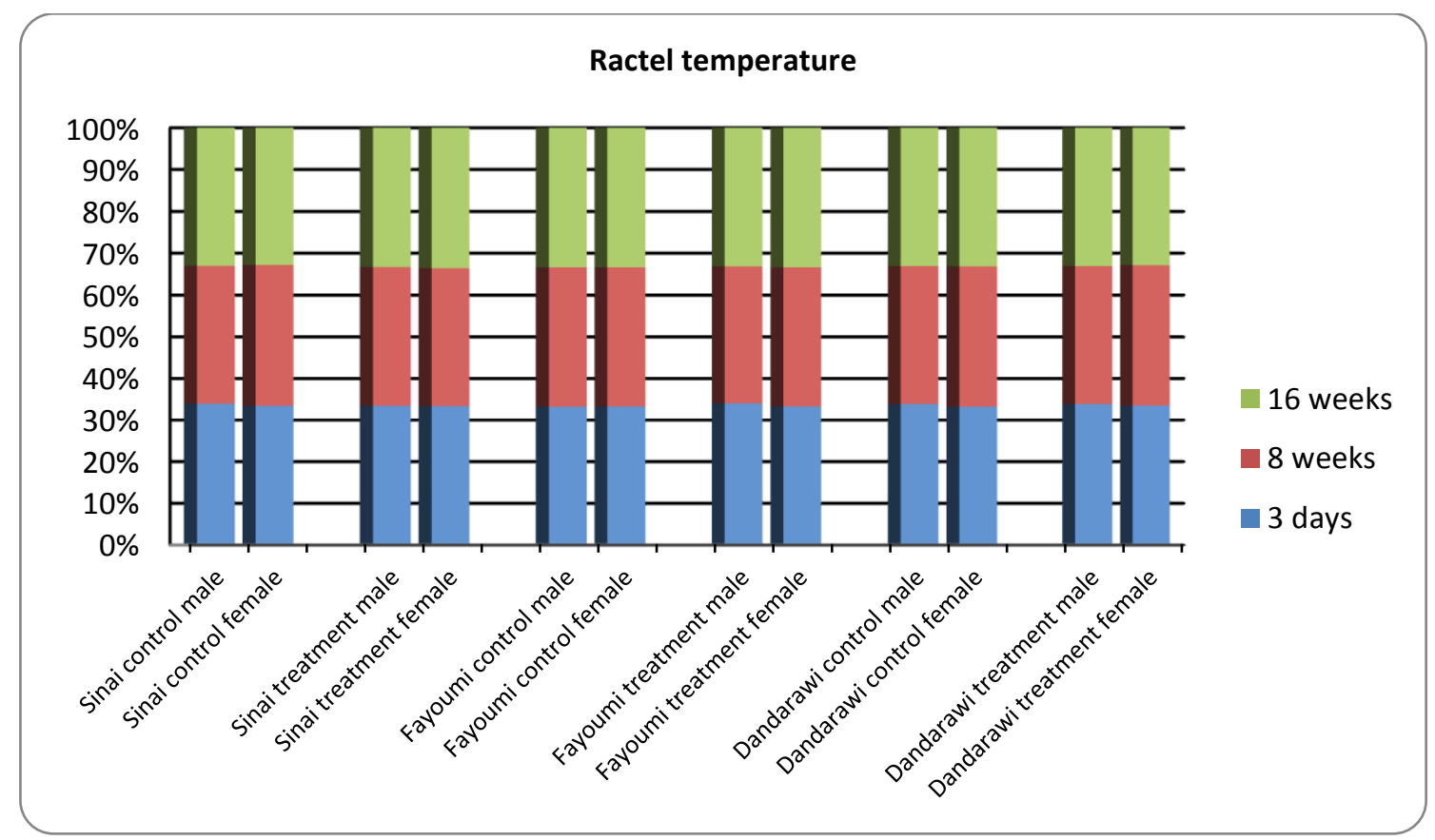

Fig. 2. Rectal temperature of Sinai, Dandarawi and Fayoumi for parent stock 


\section{Productive traits}

\section{Body weight (BW)}

Body weights of local breeds in Table $(1,2)$

\section{Males}

Effect of breeds, treatment, age and their interaction on of body weight for Fayoumi and Sinai and Dandarawi breed's parents (male) are summarized in Table (1). It could observed that Fayoumi breed males were significantly heavier body Weight at different of age in this study compared to Sinai and Dandarawi ones. However, the heat treatment was a significant decrease body weight at different age from these studies. This result agreement with Aljuobori et al (2016). They observed that the high ambient temperature was depressed the growth performance of birds duo to increase feed conversion ratio.

\section{Females}

Effects of breeds, treatment,age and their interaction on of body weight for Fayoumi and Sinai and Dandarawi breed's parents (female) data presented in Table (2). The same trend was observed in female sex compared to the male counterparts. Also, the heat treatment was a significant decrease body weight at different age from these studies. This result agrees Aljuobori et al (2016); that the high ambient temperature was depressed growth performance of birds.

Table 1. Means $\pm S E$ of effect of breeds, age , treatment and their interaction on of body weight for Fayoumi and Sinai and Dandarawi breed's parents (male).

\begin{tabular}{|c|c|c|c|c|c|c|c|c|c|c|}
\hline \multirow[t]{2}{*}{ Breeds (B) } & \multicolumn{2}{|l|}{ Treatment(T) } & \multirow[t]{2}{*}{ Overall } & \multicolumn{7}{|l|}{ Prob. } \\
\hline & Control & Heat & & A & $\mathbf{T}$ & B & $A^{*} T$ & $A^{*} B$ & $\mathbf{T}^{\star} \mathrm{B}$ & $A^{\star} T^{\star} B$ \\
\hline \multicolumn{11}{|l|}{8 weeks } \\
\hline Fayoumi & $509.78 \pm 25.55$ & $504.18 \pm 37.69$ & $506.98^{\mathrm{AA}}$ & 0.001 & 0.001 & 0.001 & 0.0001 & 0.001 & NS & 0.0001 \\
\hline Dandarawi & $469.12 \pm 17.2$ & $440.40 \pm 10.9$ & $454.76^{C}$ & & & & & & & \\
\hline Sinai & $468.63 \pm 13.54$ & $490.56 \pm 14.56$ & $479.59^{B}$ & & & & & & & \\
\hline Overall & $482.51^{A}$ & $478.38^{B}$ & & & & & & & & \\
\hline \multicolumn{11}{|l|}{10 weeks } \\
\hline Fayoumi & $647.80 \pm 28.93$ & $767.50 \pm 42.63$ & $707.65^{A}$ & & & & & & & \\
\hline Dandarawi & $579.00 \pm 20.08$ & $565.61 \pm 21.1$ & $572.305^{c}$ & & & & & & & \\
\hline Sinai & $597.61 \pm 23.69$ & $626.84 \pm 15.27$ & $612.22^{B}$ & & & & & & & \\
\hline Overall & $608.136^{B}$ & $653.31^{A}$ & & & & & & & & \\
\hline \multicolumn{11}{|l|}{12 weeks } \\
\hline Fayoumi & $914.30 \pm 42.43$ & $853.36 \pm 60.14$ & $883.83^{\mathrm{AA}}$ & & & & & & & \\
\hline Dandarawi & $708.90 \pm 25.50$ & $693.21 \pm 30.7$ & $701.055^{c}$ & & & & & & & \\
\hline Sinai & $736.33 \pm 23.73$ & $720.42 \pm 23.89$ & $728.375^{B}$ & & & & & & & \\
\hline Overall & $786.51^{A}$ & $755.66^{\mathrm{B}}$ & & & & & & & & \\
\hline \multicolumn{11}{|l|}{14 weeks } \\
\hline Fayoumi & $1107.8 \pm 58.10$ & $942.50 \pm 84.53$ & $1025.15^{\mathrm{AA}}$ & & & & & & & \\
\hline Dandarawi & $902.93 \pm 30.01$ & $631.26 \pm 35.15$ & $767.095^{\mathrm{C}}$ & & & & & & & \\
\hline Sinai & $887.00 \pm 33.90$ & $798.21 \pm 48.04$ & $842.605^{B}$ & & & & & & & \\
\hline Overall & $965.91^{\mathrm{AA}}$ & $790.65^{B}$ & & & & & & & & \\
\hline \multicolumn{11}{|l|}{16 weeks } \\
\hline Fayoumi & $1155.1 \pm 128.3$ & $1116.6 \pm 61.95$ & $1135.85^{\mathrm{AA}}$ & & & & & & & \\
\hline Dandarawi & $946.69 \pm 61.7$ & $818.18 \pm 58.29$ & $882.435^{c}$ & & & & & & & \\
\hline Sinai & $987.00 \pm 40.04$ & $912.26 \pm 40.00$ & $949.63^{B}$ & & & & & & & \\
\hline Overall & $1029.59^{A}$ & $949.01^{\mathrm{B}}$ & & & & & & & & \\
\hline
\end{tabular}

$A=$ Age, $T=$ Treatment, $B=$ Breeds. $a, b, c$ values in the same row for each parameter with different letters are significantly different $(P<0.05)$. NS, not significant 
Table 2. Means $\pm S E$ of effect of breeds, age, treatment and their interaction on of body weight for Fayoumi and Sinai and Dandarawi breed's parents (female).

\begin{tabular}{|c|c|c|c|c|c|c|c|c|c|c|}
\hline \multirow[t]{2}{*}{ Breeds (B) } & \multicolumn{2}{|l|}{ Treatment(T) } & \multirow[t]{2}{*}{ Overall } & \multicolumn{7}{|l|}{ Prob. } \\
\hline & Control & Heat & & A & $\mathbf{T}$ & B & $A^{\star} T$ & $A^{*} B$ & $T^{\star} B$ & $A^{\star} T^{\star} B$ \\
\hline \multicolumn{11}{|l|}{8 weeks } \\
\hline Fayoumi & $422.57 \pm 11.42$ & $466.07 \pm 9.38$ & $444.32^{A}$ & 0.001 & 0.001 & 0.001 & 0.001 & NS & NS & 0.0001 \\
\hline Dandarawi & $419.53 \pm 8.39$ & $436.50 \pm 10.8$ & $428.01^{\mathrm{BB}}$ & & & & & & & \\
\hline Sinai & $400.50 \pm 7.1$ & $441.87 \pm 10.8$ & $411.85^{B}$ & & & & & & & \\
\hline Overall & $414.2^{B}$ & $448.14^{A}$ & & & & & & & & \\
\hline \multicolumn{11}{|l|}{10 weeks } \\
\hline Fayoumi & $522.03 \pm 16.56$ & $613.66 \pm 11.77$ & $567.89^{A}$ & & & & & & & \\
\hline Dandarawi & $477.12 \pm 11.6$ & $541.11 \pm 10.38$ & $509.11^{c}$ & & & & & & & \\
\hline Sinai & $472.55 \pm 12.7$ & $554.65 \pm 16.07$ & $513.6^{\mathrm{B}}$ & & & & & & & \\
\hline Overall & $490.56^{A}$ & $569.80^{B}$ & & & & & & & & \\
\hline \multicolumn{11}{|l|}{12 weeks } \\
\hline Fayoumi & $703.93 \pm 24.32$ & $688.69 \pm 19.88$ & $696.31^{A}$ & & & & & & & \\
\hline Dandarawi & $608.40 \pm 20.5$ & $604.58 \pm 16.14$ & $606.49^{c}$ & & & & & & & \\
\hline Sinai & $622.19 \pm 15.63$ & $634.27 \pm 24.5$ & $628.23^{B}$ & & & & & & & \\
\hline Overall & $644.84^{A}$ & $642.51^{B}$ & & & & & & & & \\
\hline \multicolumn{11}{|l|}{14 weeks } \\
\hline Fayoumi & $810.80 \pm 27.75$ & $687.94 \pm 19.01$ & $749.37^{A}$ & & & & & & & \\
\hline Dandarawi & $731.84 \pm 20.6$ & $596.69 \pm 21.1$ & $664.265^{c}$ & & & & & & & \\
\hline Sinai & $695.41 \pm 19.98$ & $691.77 \pm 25.7$ & $693.59^{B}$ & & & & & & & \\
\hline Overall & $746.01^{A}$ & $658.8^{B}$ & & & & & & & & \\
\hline \multicolumn{11}{|l|}{16 weeks } \\
\hline Fayoumi & $859.41 \pm 29.6$ & $809.22 \pm 20.08$ & $834.31^{A}$ & & & & & & & \\
\hline Dandarawi & $774.90 \pm 29.6$ & $695.58 \pm 19.3$ & $735.24^{c}$ & & & & & & & \\
\hline Sinai & $778.00 \pm 21.8$ & $784.40 \pm 22.50$ & $781.2^{\mathrm{B}}$ & & & & & & & \\
\hline Overall & $804.10^{A}$ & $763.06^{B}$ & & & & & & & & \\
\hline
\end{tabular}

\section{Body measurements}

Effect of breeds, age, treatment and their interaction on of body measurements during growth period for Fayoumi and Sinai and Dandarawi breeds for parents. (Male and female) are summarized in Tables (3 and 4 ).

\section{Males and females}

\section{Shank length}

The Fayoumi had significantly longer shank bone compared to Sinai and Dandarawi breeds at different ages. Also, males had significantly longer shank length compared to female. While, the heat treatment was no significant effect compared to control groups. Also, the interaction between (breeds * ages) and (treatment *breeds) were no significant. This result confirmed by Yakoub (2006) observed that Fayoumi breed had significantly longer shank length compared to both Dandarawi (crested or non-crested) at 4, 12 and 16 weeks of age.

\section{Tibiai length}

The results showed that the effect of tibia length of the breed was greater in Fayoumi, followed by Sinai and Dandrawi ones.Showed the effect Tibia length has a significant between breeds, ages and treatments. Results showed that the effect of Tibia length of sex was greater males than females.

\section{Keel length}

The Fayoumi had significantly longer keel length compared to Sinai and Dandarawi breeds at different ages. Also, males had significantly longer keel length compared to females. While, the heat treatment effect not significant.But, the interaction between breeds, ages and treatment were significant. 
Table 3. Means $\pm S E$ of effect of breeds,age, treatment and their interaction on of body measurements during growth period for Fayoumi and Sinai and Dandarawi breeds parents. (Male)

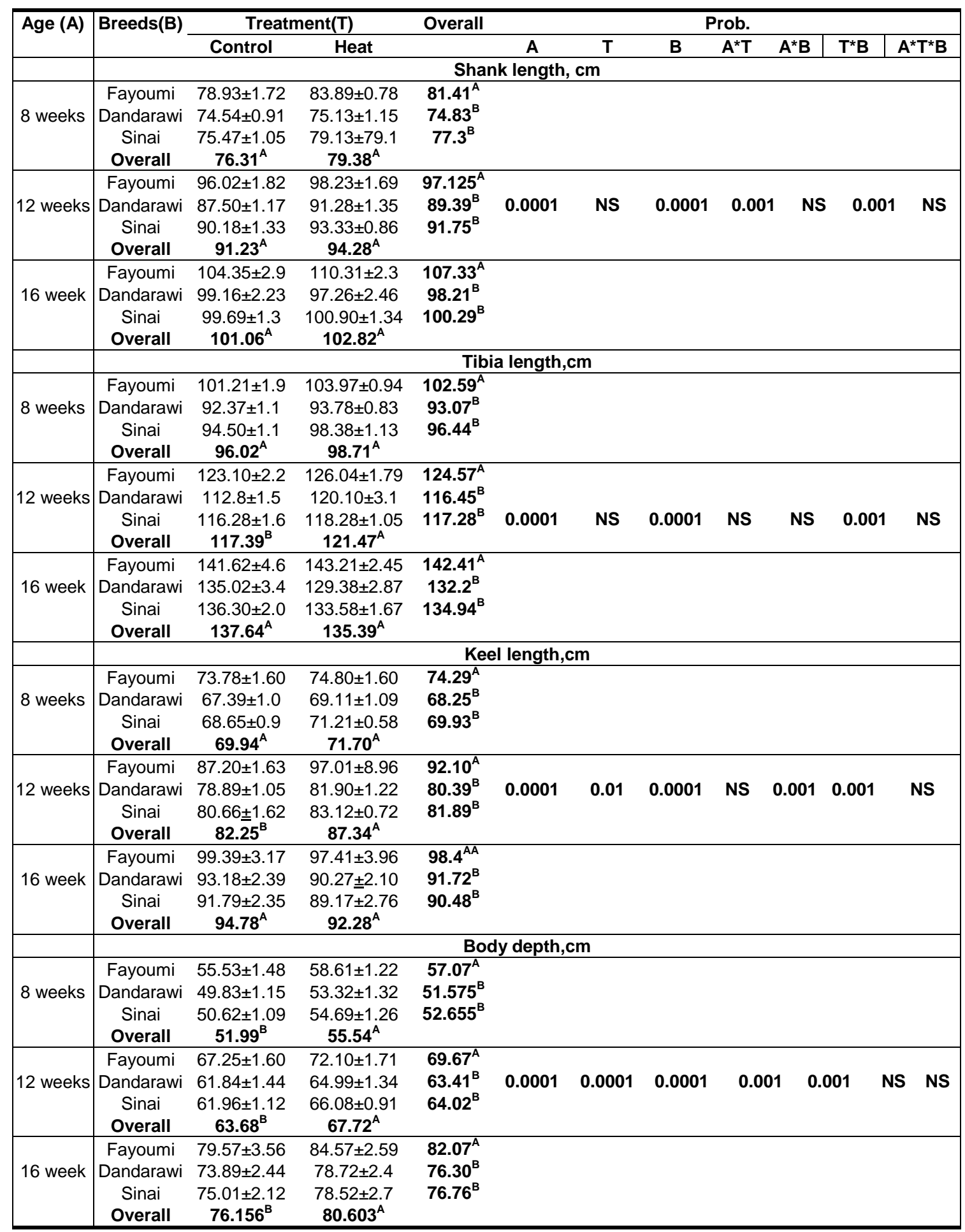


Table 4. Means $\pm S E$ of effect of breeds, age , treatment and their interaction on of body measurements during growth period for Fayoumi and Sinai and Dandarawi breeds parents. (Female)

\begin{tabular}{|c|c|c|c|c|c|c|c|c|c|c|c|}
\hline Age (A) & Breeds (B) & Treatment(T) & & Overall & Prob. & & & & & & \\
\hline & & Control & Heat & & A & $\mathbf{T}$ & B & $A^{\star} T$ & $A^{\star} B$ & $T^{\star} B$ & $A^{\star} T^{\star} B$ \\
\hline & Shank length, c & & & & & & & & & & \\
\hline & Fayoumi & $71.4 \pm 0.89$ & $76.9 \pm 0.73$ & $74.15^{A}$ & & & & & & & \\
\hline 8 weeks & Dandarawi & $69.84 \pm 0.5$ & $75.03 \pm 0.5$ & $72.43^{B}$ & 0.0001 & 0.0001 & 0.0001 & 0.001 & NS & 0.001 & NS \\
\hline & Sinai & $69.07 \pm 0.4$ & $76.26 \pm 0.92$ & $72.66^{\mathrm{B}}$ & & & & & & & \\
\hline & Overall & $70.103^{B}$ & $76.063^{A}$ & & & & & & & & \\
\hline & Fayoumi & $83.48 \pm 1.1$ & $88.7 \pm 0.73$ & $86.09^{A}$ & & & & & & & \\
\hline 12 weeks & Dandarawi & $79.17 \pm 1.8$ & $83.88 \pm 1.1$ & $81.525^{B}$ & & & & & & & \\
\hline & Sinai & $79.07 \pm 0.67$ & $86.51 \pm 0.82$ & & & & & & & & \\
\hline & Overall & $80.57^{B}$ & $86.36^{A}$ & & & & & & & & \\
\hline & Fayoumi & $90.6 \pm 1.48$ & $91.2 \pm 0.73$ & $90.9^{A}$ & & & & & & & \\
\hline 16 week & Dandarawi & $87.31 \pm 1.1$ & $87.48 \pm 0.9$ & $87.39^{B}$ & & & & & & & \\
\hline & Sinai & $84.57 \pm 0.58$ & $89.99 \pm 0.95$ & $87.28^{B}$ & & & & & & & \\
\hline & Overall & $87.49^{\mathrm{A}}$ & $89.55^{A}$ & & & & & & & & \\
\hline & Tibia length,cm & & & & & & & & & & \\
\hline & Fayoumi & $91.34 \pm 1.09$ & $96.63 \pm 0.7$ & $93.98^{A}$ & & & & & & & \\
\hline 8 weeks & Dandarawi & $89.34 \pm 0.6$ & $94.29 \pm 0.7$ & $91.81^{A}$ & & & & & & & \\
\hline & Sinai & $88.88 \pm 0.63$ & $96.17 \pm 0.77$ & $92.525^{A}$ & 0.0001 & NS & 0.0001 & NS & NS & 0.001 & NS \\
\hline & Overall & $89.853^{B}$ & $95.696^{A}$ & & & & & & & & \\
\hline & Fayoumi & $109.76 \pm 1.7$ & $118.12 \pm 1.3$ & $113.94^{A}$ & & & & & & & \\
\hline 12 weeks & Dandarawi & $106.40 \pm 2.39$ & $112.96 \pm 1.6$ & $109.68^{B}$ & & & & & & & \\
\hline & Sinai & $105.55 \pm 0.87$ & $113.88 \pm 1.13$ & $109.71^{B}$ & & & & & & & \\
\hline & Overall & $107.23^{B}$ & $114.98^{\mathrm{A}}$ & & & & & & & & \\
\hline & Fayoumi & $125.30 \pm 1.7$ & $124.97 \pm 0.8$ & $125.13^{A}$ & & & & & & & \\
\hline 16 week & Dandarawi & $121.13 \pm 1.46$ & $119.79 \pm 1.20$ & $120.46^{B}$ & & & & & & & \\
\hline & Sinai & $118.59 \pm 1.0$ & $122.67 \pm 1.0$ & $120.63^{B}$ & & & & & & & \\
\hline & Overall & $121.67^{\bar{A}}$ & $122.47^{\bar{A}}$ & & & & & & & & \\
\hline & Keel length,cm & & & & & & & & & & \\
\hline & Fayoumi & $66.95 \pm 0.81$ & $71.75 \pm 0.56$ & $69.35^{A}$ & & & & & & & \\
\hline 8 weeks & Dandarawi & $63.94 \pm 0.67$ & $67.02 \pm 0.71$ & $65.48^{A}$ & & & & & & & \\
\hline & Sinai & $64.93 \pm 0.54$ & $69.66 \pm 0.65$ & $67.29^{A}$ & 0.0001 & 0.01 & 0.0001 & NS & 0.001 & 0.001 & NS \\
\hline & Overall & $65.27^{A}$ & $69.47^{A}$ & & & & & & & & \\
\hline & Fayoumi & $78.23 \pm 1.22$ & $82.95 \pm 0.86$ & $80.59^{A}$ & & & & & & & \\
\hline 12 weeks & Dandarawi & $74.47 \pm 1.79$ & $77.13 \pm 1.18$ & $75.8^{\mathrm{A}}$ & & & & & & & \\
\hline & Sinai & $75.07 \pm 0.85$ & $78.71 \pm 1.56$ & $76.89^{A}$ & & & & & & & \\
\hline & Overall & $75.92^{\mathrm{A}}$ & $79.59^{\mathrm{A}}$ & & & & & & & & \\
\hline & Fayoumi & $91.20 \pm 1.54$ & $88.97 \pm 1.06$ & $90.08^{A}$ & & & & & & & \\
\hline 16 week & Dandarawi & $87.69 \pm 1.12$ & $85.95 \pm 0.96$ & $86.82^{A}$ & & & & & & & \\
\hline & Sinai & $87.02 \pm 0.89$ & $90.61 \pm 1.03$ & $88.81^{A}$ & & & & & & & \\
\hline & Overall & $88.63^{\mathrm{A}}$ & $88.51^{A}$ & & & & & & & & \\
\hline & Body depth,cm & & & & & & & & & & \\
\hline & Fayoumi & $51.35 \pm 0.79$ & $54.35 \pm 0.63$ & $52.85^{A}$ & & & & & & & \\
\hline 8 weeks & Dandarawi & $48.19 \pm 0.56$ & $51.81 \pm 0.86$ & $50^{A}$ & & & & & & & \\
\hline & Sinai & $48.56 \pm 0.68$ & $54.85 \pm 0.83$ & $51.70^{A}$ & & & & & & & \\
\hline & Overall & $49.36^{A}$ & $53.67^{\mathrm{AA}}$ & & & & & & & & \\
\hline & Fayoumi & $61.61 \pm 0.95$ & $68.20 \pm 0.84$ & $64.90^{\mathrm{A}}$ & & & & & & & \\
\hline 12 weeks & Dandarawi & $66.66 \pm 8.07$ & $62.87 \pm 0.83$ & $64.76^{A}$ & 0.0001 & 0.0001 & 0.0001 & 0.001 & 0.001 & 1 NS & NS \\
\hline & Sinai & $59.53 \pm 0.84$ & $64.78 \pm 0.93$ & $62.15^{\mathrm{A}}$ & & & & & & & \\
\hline & Overall & $62.6^{\mathrm{A}}$ & $65.28^{\mathrm{AA}}$ & & & & & & & & \\
\hline & Fayoumi & $74.81 \pm 1.42$ & $80.31 \pm 1.17$ & $77.56^{A}$ & & & & & & & \\
\hline 16 week & Dandarawi & $71.76 \pm 2.15$ & $75.48 \pm 1.3$ & $73.62^{A}$ & & & & & & & \\
\hline & Sinai & $72.25 \pm 1.11$ & $77.85 \pm 1.30$ & $75.05^{A}$ & & & & & & & \\
\hline & Overall & $72.94^{\mathrm{A}}$ & $77.88^{\mathrm{A}}$ & & & & & & & & \\
\hline
\end{tabular}


This result was agreement with Hussen et al (2000) shows that, Fayoumi breed birds had the longest keel bone at 8,12 and 16 weeks of age compared with Dandarawi breed.

\section{Body depth}

The Fayoumi breed had high significantly deeper body depth than Sinai and Dandrawi at different ages in both sexes. The males were significant deeper body depth than female. Also, the heat treatment effect was significant decrease body depth than control groups. While, all type interactions were highly significant. This result sustained by Hussen et al (2000) found that there was a significant difference between Fayoumi and Dandarawi breed for body depth character at different ages, also the interaction between strain and sex was not significant, that Fayoumi breed was significantly deeper body depth compared to Dandarawi one at $4,8,12$ and 16 weeks of age.

\section{REFERENCES}

Aljuobori, A., Zulkifli I., Soleimani, A.F., Abdullah N., Liang, J.B. and Mujahid, A. 2016 Higher inclusion rate of canola meal under high ambient temperature for broiler chickens. Poult Sci., 95(6), 1326-1331.

Arad, Z. and Marder J. 1982. Comparison of the productive performances of the Sinai Bedouin fowl, the white leghorn and their crossbreds: Study under natural desert conditions. British Poultry Science, Volume 23(4), 163-170.

Arjona, A.A., Denbow D.M. and Weaver W.D. 1990. Neonatally-induced thermotolerance: Physiological responses, British Poultry Science. 95(3), 393-399.

Blagojevic, D.P. 2007. Antioxidant systems in supporting environmental and programmed adaptations to low temperatures. Cryo-Letters. 28(7), 137-150.

Carmen, A., Deeb N. and Gutman M. 1991. Effects of the plumage-reducing naked neck $(\mathrm{Na})$ gene on the performance of fast growing broilers at normal and high ambient temperatures. Poult. Sci., 72, 775-767.

Donal A. Walsh, Charles D. Ashby, Carmen Gonzalez, Dianne Calkins, Edmond $H$. Fischer and Edwin G. Krebs, 1977. Purification and Characterization of a Protein Inhibitor of Adenosine 3',5'-Monophosphate-dependent Protein Kinases. The Journal of Biological Chemistry April (10), 246 -1985.

Emery, J. 2004. Heat stresses in poultry-Solving the problem. Defra Publications (ADAS)., http://www.alpharma.com.

Howlider, M.A.R. and Rose, S.P. 1989. Rearing temperature and the meat Yield of broilers. $\mathbf{B r}$ Poult. Sci., 30, 61-67.

Hussen, SH.H.; Fathi M.M. and Galal A. 2000. Residual feed consumption in three local genotype of chicken segregating for naked neck gene. Egyp. Poult. Sci., 20, 311-326.

Meehl, G.A. and Tebaldi C. 2004. Global Change heat stress, Science. 305, 994-997.

Obike, O.M., Ukoha O.A. and Emmanuel F.H. 2016. Growth performance, linear measurment and costbenefit of two strains of broiler chickens in a tropical enviromental. Nigerian Journal of Agriculture Food and Environment. 12(1), 90-94.

Ozbey, O. and Ozceilik, M. 2004. The effect of high environmental temperature on growth performance of Japanese quails with different body weight. Int. J. Poult. Sci., 3, 468-470.

Renaudeau, D., Collin, A., Yahav, S., De Basilio, V., Gourdine, J.L. and Collier, R.J. 2012. Adaptation to hot climate and strategies to alleviate heat stress in livestock. Production Animal. 6, 707-728.

Sayda M. Elbashir, Jens Harborth, Winfried Lendeckel, Abdullah Yalcin, Klaus Weber and Thomas Tuschl, 2001. Duplexes of 21nucleotide RNAs mediate RNA interference in cultured mammalian cells. Nature, 411(24), 494-498.

Turnpenny, J.R., Parsons D.J. and Armstrong, A.C. 2001. Global change. Production Animal Sci., 7, 163-170.

Yahav, S. Hurwitz 1996. Induction of Thermo tolerance in Male Broiler Chickens by Temperature Conditioning at an Early Age. Poult Sci., 75 (3), 402-406.

Yakoub, H.A.M.A., 2006. Immunogenic measurements as a tool for selection in some local Chicken Breeds. M.Sc. Thesis, Fac. of Agric. Ain shams Univ., Egypt.

Younis, H.H., Abd El-Ghany F.A. and Oskan 2003. Productive and reproductive performance of four local chicken strains during winter and summer seasons. Egypt. Poult Sci., 23, 893-910. 